\title{
Travel and cognitive dissonance
}

\author{
Jonas De Vos ${ }^{a,}{ }^{*}$, Patrick A. Singleton ${ }^{b}$ \\ ${ }^{a}$ Bartlett School of Planning, University College London \\ ${ }^{\mathrm{b}}$ Department of Civil and Environmental Engineering, Utah State University \\ * Corresponding author: 14 Upper Woburn Place, London WC1H 0NN, United Kingdom \\ Telephone: +44(0)20 3108 9867; E-mail: jonas.devos@ucl.ac.uk \\ ORCID: 0000-0003-4919-2157 (J. De Vos); 0000-0002-9319-2333 (P.A. Singleton)
}

\begin{abstract}
In this review paper, we reconceptualise the relationships between travel-related attitudes and behaviours using (and considering the applicability of) Festinger's cognitive dissonance theory. According to this psychological theory - developed in the 1950s and widely used ever since - a dissonance between attitudes and behaviour can result in feelings of discomfort, which people will try to reduce by changing either their attitudes or their behaviour. In our interpretation, we focus on two interrelated decision processes linked with travel behaviour, i.e., travel mode choice and residential location choice. Although a considerable number of travel behaviour studies refer to the cognitive dissonance theory in order to explain found results (e.g., changed attitudes), a full examination of the process of cognitive dissonance (reduction) in the travel behaviour literature is currently lacking. Through this critical consolidation of transport literature on the cognitive dissonance topic, we propose future research directions to fill this gap. We argue that the cognitive dissonance theory can provide valuable insights into satisfaction levels with travel and the place of residence, while also helping to explain changes in travel-related attitudes and choices of where to live and which travel mode to use.
\end{abstract}

Keywords: Travel behaviour; Cognitive dissonance; Travel mode choice; Residential location choice; Travel satisfaction; Residential self-selection 


\section{Introduction}

Travel behaviour research has long been interested in studying the importance of attitudes on travel choices, and many studies - mainly since the 1990s (e.g., Kitamura et al., 1997) but dating back to the 1970s and earlier (e.g., Tardiff, 1977) - have examined these complex relationships. Attitudes towards specific travel modes can directly impact travel through a propensity to use those modes, but also indirectly through the residential location choice: people may choose a neighbourhood that enables use of these preferred means of transportation (e.g., Handy et al., 2005; Schwanen \& Mokhtarian, 2005a). However, certain constraints may restrict the use of a desired travel mode or the ability to live in a desired type of neighbourhood. In these cases, a dissonance between attitudes and behaviour can negatively affect travel and/or residential satisfaction. Responses to low satisfaction levels can include behaviour change (choosing a different mode or moving to another neighbourhood) or travel-related attitude change (to better match current travel patterns or residential areas).

In this review paper, we will apply cognitive dissonance theory (Festinger, 1957) to examine these relationships between transportation-related behaviours, attitudes, and satisfaction. Our goals are: (1) to review the applicability of cognitive dissonance theory for understanding relationships between travel-related attitudes, behaviours, and satisfaction associated with travel modes and residential locations; and (2) to offer implications for policymaking and recommendations for a future research agenda on this topic. In this introduction we will first describe the theory of cognitive dissonance before performing a literature search on studies applying this theory in the travel behaviour field.

\subsection{Cognitive dissonance theory}

“... the habitual cigarette smoker who has learned that smoking is bad for his health ... might simply change his cognition about his behavior by changing his actions; that is, he might stop smoking. If he no longer smokes, then his cognition of what he does will be consonant with the knowledge that smoking is bad for his health. ... the person who continues to smoke, knowing that it is bad for his health, may also feel (a) he enjoys smoking so much it is worth it; (b) the chances of his health suffering are not as serious as some would make out; (c) he can't always avoid every possible dangerous contingency and still live; and (d) perhaps even if he stopped smoking he would put on weight which is equally bad for his health. So, continuing to smoke is, after all, consistent with the idea about smoking" (Festinger, 1957, pp. 2, 5-6)

The habitual cigarette smoker's concern is a famous example of how a conflict between behaviour and belief can result in changing opinions or changing actions. According to the well-known theory of cognitive dissonance (Festinger, 1957, 1964) such a conflict occurs in cases of internal inconsistencies in terms of opinions, attitudes and behaviour. This dissonance can relate to conflicting attitudes (e.g., an environmentally aware car fanatic), but mostly relates to a mismatch or inconsistency between attitudes and behaviour regarding a single topic (e.g., the cigarette smoker acknowledging the negative health effects of smoking). According to Festinger, such a dissonance results in psychological discomfort and feelings of frustration and dissatisfaction. Due to this state of discomfort, people will try to reduce the level of cognitive dissonance. A first way to achieve this is to change behaviour (e.g., stopping to smoke). Such an effect of satisfaction levels with a previous choice/activity on current behaviour has also been acknowledged in other, more recent, studies (Kahneman et al., 1997; Russell \& Lanius, 1984; Triandis, 1977). In case changing behaviour is not (perceived) feasible, people might 
instead change their attitudes in order to reduce dissonance. In a decision process, this can be done by attributing positive elements to the chosen alternative and negative elements to the non-chosen alternative, in order to justify the made decision (e.g., smokers deluding themselves that smoking is not that bad after all). This is in line with studies indicating that attitudes are affected by how (pleasant or unpleasant) previous activities have been perceived (Clore \& Schnall, 2005; Eagly \& Chaiken, 1993). The dissonance reduction process of cognitive dissonance theory also implies that, for sociallyundesirable behaviours (such as smoking, or automobile dependence), policies and programs aimed at improving attitudes regarding socially-desirable alternatives (not smoking; or walking, cycling, and using public transport) could be a successful approach to (health or travel) behaviour change.

The interesting aspect of this theory is that it helps explain both behaviour and attitudes, or as Festinger $(1957$, p. 3) phrases it "dissonance ... is a motivating factor in its own right. .... Cognitive dissonance can be seen as an antecedent condition which leads to activity, oriented toward dissonance reduction". The fact that this theory indicates changes in attitudes is conflicting with theories - such as the theory of planned behaviour (Ajzen, 1991) - considering attitudes to be stable constructs, partly determined by genetic factors (e.g., Bohner \& Wänke 2002; Crano \& Prislin, 2011). The cognitive dissonance theory has been one of the most influential theories in social psychology, generating hundreds of empirical studies. This theory has - over the last 60 years - been frequently used to explain attitudes and behaviour in various domains such as marketing, politics and economics (Brehm \& Cohen, 1962; Cooper, 2007; Harmon-Jones \& Mills, 1999; Wicklund \& Brehm, 1976). Festinger's work also received some criticism and witnessed a declining interest during the 1970s (Aronson, 1992; Cooper, 2007), partly due to the often experimental design of measurement resulting in limited representativeness and possible severe biases (e.g., consistency bias, social desirability). However, his theory is still being used frequently and can be regarded as a reliable framework explaining attitudes and behaviour.

As shown in Figure 1, our use of cognitive dissonance theory (in a travel behaviour context) will focus on a dissonance between attitudes and behaviour, thus excluding from consideration dissonances between various attitudes. Although Festinger (1957) also uses the terms "opinions", "beliefs" and "values", we will use the term "attitudes" in the remainder of this paper. An attitude can be defined as the degree of a favourable or unfavourable evaluation or appraisal of a certain person, object or behaviour (see, for instance, Eagly \& Chaiken, 1993; Triandis, 1971; Zanna \& Rempel, 1988). Although Festinger (1957) refers to the situation of cognitive dissonance as being "psychologically uncomfortable", we will mainly refer to "(dis)satisfaction" to describe this state of mind, since this term is used more frequently in travel behaviour studies. Although the cognitive dissonance theory is closely related with theories such as the balance theory (Heider, 1958) and the self-perception theory (Bem 1967), we will only focus on the cognitive dissonance theory.

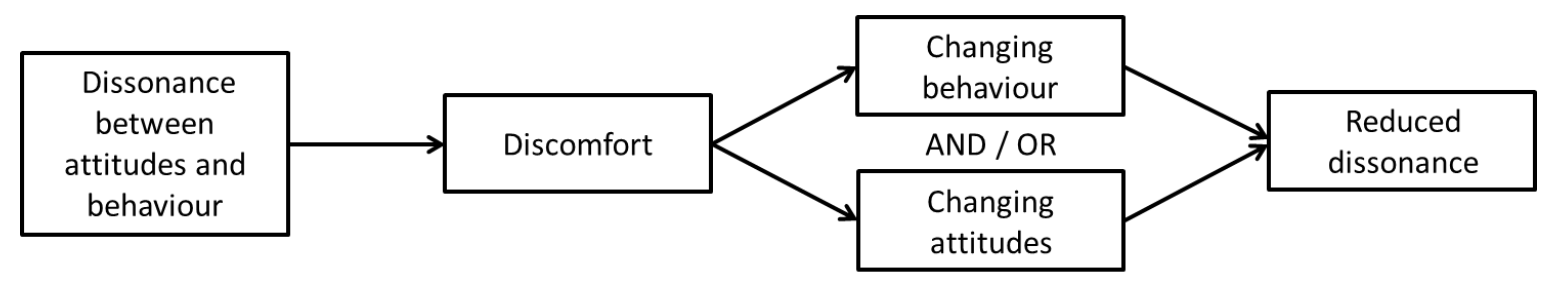

Figure 1. Cognitive dissonance (reduction) (based on: Festinger, 1957) 


\subsection{Cognitive dissonance theory in existing transportation studies: A literature search}

The concept of cognitive dissonance (reduction) - although providing possible explanations for satisfaction levels and potential changes in attitudes and behaviour - has only received limited attention in travel behaviour studies. A search in Web of Science and in various transportation journals ${ }^{1}$ resulted in 49 studies - referring to or having a clear link with the cognitive dissonance theory - being selected (final search: January 2020). The following keywords were used when searching for studies: "travel" OR "transport" AND "dissonance" OR "residential dissonance" OR "mismatch" (i.e., 6 combinations). No date restrictions or snowballing techniques were applied in our search, and searches were limited to English and full (peer-reviewed) journal articles (excluding conference proceedings, policy documents, etc.). Review papers or papers only mentioning this theory in their literature review were excluded. Furthermore, we only selected studies that analysed attitudes towards travel (modes) and/or residential location, and focussing on travel mode choice and/or the residential location choice. Table 1 provides an overview of the travel behaviour papers found in our literature search.

It is interesting to note that many of the included studies do not focus on cognitive dissonance itself, but instead refer to this theory as a possible explanation of found results. We interpret this to mean that many travel behaviour researchers may not be focused on explicitly testing the validity of cognitive dissonance theory or even utilising it for the design of studies; rather, they may simply find the theory to be a useful framework for interpreting their results (although exceptions exist, such as Kroesen et al. (2017) and Lin et al. (2017)). To us, this is a missed opportunity, as cognitive dissonance theory offers an explicit structural framework of relationships between attitudes, behaviour, and satisfaction that can be used for hypothesis testing.

In order to structure our survey of the literature, we divided travel behaviour studies incorporating the cognitive dissonance theory into two groups: (1) those focussing on a (possible) dissonance between travel attitudes and chosen travel mode(s), and (2) those focussing on a (possible) dissonance between travel-related attitudes and people's residential location. As shown in Table 1, we further subdivided studies in each group into specific topic areas. Within the first group, most studies refer to the cognitive dissonance theory to explain changes in travel attitudes. These studies suggest that people change their mode-specific attitudes so they better match with the chosen travel mode. Within the second group, most studies focus on the effect of people's residential environment on travel-related attitudes, or on the effect of residential dissonance on people's travel behaviour (as people not living in a neighbourhood stimulating their preferred travel mode(s) might be forced to adapt their travel behaviour).

\footnotetext{
1 The following journals were screened: Transportation Research Part A, Transportation Research Part D, Transportation Research Part F, Transportation, Journal of Transport Geography, Journal of Transport and Land Use, Transport Policy, International Journal of Sustainable Transportation, and Travel Behaviour and Society.
} 
Table 1. Empirical travel behaviour studies linked to the cognitive dissonance theory

\begin{tabular}{|c|c|c|}
\hline $\begin{array}{l}\text { Type of } \\
\text { dissonance }\end{array}$ & $\begin{array}{l}\text { Link of study with cognitive } \\
\text { dissonance }\end{array}$ & Empirical studies \\
\hline \multirow{3}{*}{$\begin{array}{l}\text { Dissonance } \\
\text { between travel } \\
\text { attitudes and } \\
\text { chosen mode } \\
\text { (travel mode } \\
\text { dissonance) }\end{array}$} & $\begin{array}{l}\text { Extent of travel mode } \\
\text { dissonance }\end{array}$ & $\begin{array}{l}\text { De Vos (2018); Kroesen et al. (2017); Stark et al. } \\
\text { (2019); Ton et al. (2019); Li (2018); Zarabi et al. } \\
(2019)\end{array}$ \\
\hline & $\begin{array}{l}\text { Changing attitudes towards } \\
\text { chosen travel mode (in } \\
\text { order to reduce travel } \\
\text { mode dissonance) }\end{array}$ & $\begin{array}{l}\text { Belgiawan et al. (2016); Chen \& Lai (2011); } \\
\text { Domarchi et al. (2008); Fu et al. (2018); Horowitz } \\
\text { (1978); Kaplan et al. (2014); Kroesen et al. (2017); } \\
\text { Reibstein et al. (1980); Stark et al. (2018); Susilo \& } \\
\text { Cats (2014); Thigpen (2019); Wang \& Chen (2012) }\end{array}$ \\
\hline & $\begin{array}{l}\text { Effect of travel mode } \\
\text { dissonance on travel } \\
\text { satisfaction }\end{array}$ & $\begin{array}{l}\text { Abou-Zeid \& Fujii (2016); De Vos (2018); Stark et } \\
\text { al. (2019); Ye \& Titheridge (2019); Zarabi et al. } \\
\text { (2019) }\end{array}$ \\
\hline \multirow{6}{*}{$\begin{array}{l}\text { Dissonance } \\
\text { between travel } \\
\text { attitudes and } \\
\text { residential } \\
\text { location } \\
\text { (residential } \\
\text { dissonance) }\end{array}$} & $\begin{array}{l}\text { Extent of residential } \\
\text { dissonance }\end{array}$ & $\begin{array}{l}\text { Ettema \& Nieuwenhuis (2017); Kamruzzaman et al. } \\
\text { (2016); Schwanen \& Mokhtarian (2004) }\end{array}$ \\
\hline & $\begin{array}{l}\text { Changing attitudes towards } \\
\text { chosen neighbourhood (in } \\
\text { order to reduce residential } \\
\text { dissonance) }\end{array}$ & $\begin{array}{l}\text { Bagley \& Mokhtarian (2002); De Vos et al. (2018); } \\
\text { Lin et al. (2017); Páez (2013); van de Coevering et } \\
\text { al. (2016, 2018); Wang \& Lin (2019) }\end{array}$ \\
\hline & $\begin{array}{l}\text { Effect of residential } \\
\text { dissonance on travel } \\
\text { behaviour }\end{array}$ & $\begin{array}{l}\text { Cao (2015); Cho \& Rodriguez (2014); De Vos et al. } \\
\text { (2012); Frank et al. (2007); Huang et al. (2016); } \\
\text { Kajosaari et al. (2019); Kumar et al. (2018); } \\
\text { Manaugh \& El-Geneidy (2015); Næss (2009, 2010, } \\
\text { 2014); Kamruzzaman et al. (2013a, 2015); } \\
\text { Schwanen \& Mokhtarian (2005a, 2005b); Wolday } \\
\text { et al. (2018) }\end{array}$ \\
\hline & $\begin{array}{l}\text { Effect of residential } \\
\text { dissonance on travel } \\
\text { satisfaction }\end{array}$ & De Vos et al. (2016a); Milakis et al. (2015) \\
\hline & $\begin{array}{l}\text { Effect of residential } \\
\text { dissonance on residential } \\
\text { satisfaction }\end{array}$ & Cao \& Wang (2016), van de Coevering et al. (2018) \\
\hline & $\begin{array}{l}\text { Effect of residential } \\
\text { dissonance on residential } \\
\text { mobility }\end{array}$ & Kamruzzaman et al. (2013b) \\
\hline
\end{tabular}

In this paper, we use cognitive dissonance theory as a relevant lens through which to examine and structurally summarise the complex relationships and dynamics between travel-related attitudes and behaviours (specifically, travel mode choices and residential location choices) and related satisfaction levels (i.e., travel satisfaction and residential satisfaction). In Section 2, we first review and critique the travel behaviour literature on these topics using the framework of cognitive dissonance theory, focussing on travel mode choice and the residential location choice (and the interrelationships between the two). We then reconceptualise these relationships between choices, satisfaction, and attitudes in terms of theory-based processes of travel mode dissonance reduction and residential dissonance reduction. Section 3 provides a discussion of the formation and stability of dissonant and consonant states. Finally, in Section 4 we close by analysing policy implications and proposing a future research agenda to fill gaps in the literature, validate the cognitive dissonance theory, and improve understanding of these dynamics between travel behaviours and attitudes. 


\section{Review of links between cognitive dissonance and travel behaviour}

In this section we apply the cognitive dissonance theory to travel behaviour, using this framework to structure and summarise our review focusing on two decision processes, i.e., travel mode choice and residential location choice (in Sections 2.1 and 2.2, respectively). Additionally, we also look at how these two processes are related with each other (in Section 2.3).

\subsection{Travel mode choice}

Although many travel behaviour studies have indicated that attitudes have a significant effect on people's travel mode choice (e.g., Kitamura et al. 1997; Bagley \& Mokhtarian, 2002; Handy et al., 2005), few have looked at individuals' level of dissonance between mode-specific attitudes and travel mode choice (travel mode dissonance). First of all, not a lot of studies have actually measured attitudes towards the use of specific modes, nor have these attitudes towards various modes often been compared with each other, in order to detect people's preferred travel mode (De Vos, 2018). The limited amount of studies analysing mode-specific attitudes indicate that people's attitudes are most positive towards active travel, followed by driving, and most negative towards public transport (Anable \& Gatersleben, 2005; De Vos, 2018; Kroesen et al., 2017; van Wee et al., 2002), although attitudes towards train and subway are mostly more positive compared to bus attitudes (e.g., Zarabi et al., 2019).

We found six (recent) studies - from different (geographical) contexts and using various methodologies - that analysed the consistency between mode-specific attitudes and travel mode choice. De Vos (2018) indicates that about half of the respondents used a non-preferred travel mode to reach their most-recent leisure activity. Especially public transport users often have a more positive attitude towards another mode, while cyclists are generally most positive about their chosen mode. Zarabi et al. (2019), on the other hand, indicate that the most people have a positive attitude towards the used commute mode (overall dissonance level $=20.9 \%$ ), and that especially cyclists and bus users have the highest chance of being dissonant travellers (i.e., preferring other modes). Kroesen et al. (2017) found that dissonance is highest for cycling due to positive cycling attitudes and a relatively low amount of kilometres cycled (in a "regular week"), indicating that a lot of people would actually like to cycle more than they currently do. In a study focussing on children's school travel, Stark et al. (2019) found that travel mode dissonance is lowest for active travellers, and that younger children ( 8 to 9 years old) preferred active travel modes, while older children (12 to 13 years old) had stronger preferences for being driven to school. Ton et al. (2019) found a high level of travel mode consonance (especially among people with multimodal travel patterns), while active travel or train were often preferred in cases of dissonance. Finally, Li (2018) - using focus groups - indicates that dissonance often occurs as a result of high car use in combination with a preference for using public transport (train in particular).

The presence of travel mode dissonance is likely to depend on whether the travel mode choice is a free choice or a forced compliance. "Captive mode users", having limited freedom to choose their travel mode, are more likely to use low-valued travel modes than people having a lot of travel options (i.e., "choice users") (Beimborn et al., 2003; Jacques et al., 2013). This seems to be confirmed by De Vos (2018), indicating that travel mode dissonance can occur due to the absence of travel skills or travel options, or the presence of travel barriers (e.g., a person not able to ride a bicycle, having no public transport services in his/her neighbourhood, or distances being too long to cycle, respectively). 
Over the past decade a numerous amount of studies have started analysing how satisfied travellers are with their trips. Although most of them found a clear effect of the used travel mode on travel satisfaction (e.g., De Vos et al., 2016a; Morris \& Guerra, 2015; Singleton, 2019)², only a few also looked at travel satisfaction levels according to whether the chosen mode was valued or even preferred. Some studies found that satisfaction levels of trips are positively affected by a positive stance towards the chosen travel mode (De Vos et al., 2016a; Reibstein et al., 1980; St-Louis et al., 2014; Ye \& Titheridge, 2017). In line with these results, three recent studies found that satisfaction levels of people travelling with their preferred travel mode are significantly higher compared to people using a non-preferred mode (De Vos, 2018; Stark et al., 2019; Ye \& Titheridge, 2019).

These findings are in line with the cognitive dissonance theory, stating that cognitive dissonance results in feelings of discomfort. According to this theory it can also be expected that people not using a desired travel mode - and thus feeling rather unsatisfied with their trip - will try to increase travel satisfaction of future trips by choosing a different - more appreciated - mode for these trips. Of course, it is possible that choosing another mode is not an option, e.g., when car lovers are forced to use public transport because they cannot afford to buy a car, or when people who want to cycle have to use motorised transport due to long travel distances. In these cases, travel mode dissonance and low levels of travel satisfaction might be reduced more easily by improving attitudes towards the used travel mode, or by assigning negative perceptions to non-chosen travel modes. The person being forced to use public transport might feel that public transport is not so unreliable after all, while the person not being able to cycle might decide that cycling is in the end rather exhausting and unpractical.

We are unaware of (longitudinal) studies that have analysed changes in travel mode choice due to a dissonance between travel mode attitudes and mode choice, or due to the resulting low levels of travel satisfaction. Some studies did, however, look at possible effects of travel satisfaction on travel mode choice. Reibstein et al. (1980) found significant positive effects of satisfaction with bus use on the frequency of bus use. Beirão and Cabral (2007) indicate that the perceived service performance of car and public transport trips has an important effect on choosing that mode. Abou-Zeid and Ben-Akiva (2012) state that a lower satisfaction with car use and a higher satisfaction with public transport use make a mode switch from car to public transport more likely, while Singleton (2017) indicates that people might choose certain travel modes in order to obtain certain desired levels of travel satisfaction. Finally, a recent study from De Vos et al. (2019) shows that satisfying walking and cycling trips positively affect the use of active travel modes, due to improved attitudes towards these modes. However, these studies made no distinction between consonant and dissonant mode users, while they also (except for Abou-Zeid \& Ben-Akiva, 2012) used cross-sectional data making it impossible to capture changes in behaviour. Abou-Zeid and Fujii (2016) found that average levels of satisfaction with commute trips increased for habitual car users switching to public transport after receiving a one-month free public transport pass. In this study, a certain number of respondents switching to public transport indicated that using public transport made their commutes more convenient and pleasant. These people might actually have been dissonant car users, whether or not being aware of this. A change in behaviour (i.e., switching to public transport) might have reduced their (travel mode) dissonance and increased their (travel) satisfaction.

\footnotetext{
${ }^{2}$ Most studies analysing travel satisfaction link low levels of travel satisfaction with public transport use (bus use in particular), while walking and cycling are mostly associated with high travel satisfaction levels.
} 
Although most travel studies have - partly based on the theory of planned behaviour (Ajzen 1991) analysed the effect of attitudes on behaviour, some studies - often performed before Ajzen's study have also looked at potential changes in attitudes. These studies indicate that travel-related attitudes and mode choice are mutually dependent on each other and that attitudes both affect, and are affected by, choices (Dobson et al., 1978; Golob et al., 1979; Tardiff, 1977). Some studies even state that travel behaviour influences attitudes more than vice versa (Golob, 2001; Kroesen et al., 2017; Reibstein et al., 1980). Fujii and Kitamura (2003), for instance, found that attitudes towards bus use improved after a switch from car use to bus use (due to receiving a one-month free bus ticket), possibly because these people started appreciating the positive aspects of public transport after using it a couple of times. Anyway, these studies indicate that travel attitudes are more subject to change than often assumed, and some of them (i.e., Golob, 2001; Golob et al., 1979; Kroesen et al., 2017; Reibstein et al., 1980) refer to the cognitive dissonance theory to explain these changes in attitudes. According to Kroesen et al. (2017), people experiencing a dissonance between mode-specific attitudes and mode choice are more likely to adjust their attitudes than their behaviour. According to De Vos et al. (2019), the use of a certain mode can also affect attitudes towards that mode indirectly, through satisfaction with the trip undertaken.

Based on the literature described in this section, we propose a process in which people might try to reduce a possible dissonance between travel attitudes and the chosen travel mode (Figure 2). Such a travel mode dissonance may likely result in relatively low levels of travel satisfaction, causing an intention to change the mode choice for a following trip. However, in case such a modal shift is not feasible (e.g., due to budgetary or built environment constraints) people might instead change their mode-specific attitudes in order to reduce dissonance between attitudes and travel mode for future trips, so travel satisfaction of future trips will be higher. The process shown in Figure 2 consequently needs to be regarded as a cyclical process which is passed through every time a trip is undertaken.

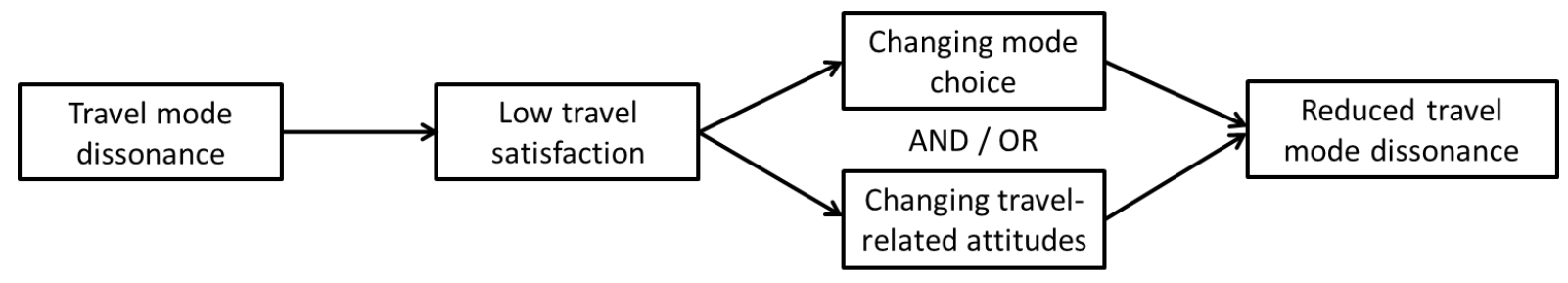

Figure 2. Travel mode dissonance (reduction)

\subsection{Residential location choice}

The residential location has an important effect on people's travel behaviour. Numerous studies have found that people living in suburban-style neighbourhoods make the majority of their trips by car, while urban residents tend to walk, cycle or use public transport rather frequently (see, for instance Ewing and Cervero, 2001, 2010). Mainly since the 1990s, studies have indicated that - besides the built environment - attitudes also play an important role in explaining travel behaviour, and travel mode choice in particular (e.g., Kitamura et al., 1997; Bagley \& Mokhtarian, 2002). Some studies claimed that attitudes can also impact travel mode choice indirectly, through the residential location choice process (e.g., Cao et al., 2009; Handy et al., 2005; Næss, 2009). People preferring to use a certain mode will try to live in a neighbourhood stimulating the use of that mode (e.g., a car lover preferring to live in a 
suburban neighbourhood; a person wishing to walk/cycle preferring to live in an urban neighbourhood). Due to this self-selection process, studies have started to claim that travel mode choice is better explained by attitudes than by the residential location. However, most studies still find significant effects from the built environment on travel behaviour, even when attitudes are accounted for (Cao et al., 2009; Ewing \& Cervero, 2010).

Although such a (transport-related) self-selection process has been put forward by a considerable number of studies, some studies found that the residential neighbourhood people live in is not always consistent with their travel-related attitudes. Such an inconsistency can be described as residential dissonance. ${ }^{3}$ In a study in the San Francisco Bay Area, Schwanen and Mokhtarian (2004, 2005a, 2005b) found that $23.6 \%$ of the respondents did not live in their preferred neighbourhood, i.e., suburban residents preferring to live in an urban, walk-friendly neighbourhood and urban residents preferring to live in a suburban, more car-oriented neighbourhood. In a Belgian study, De Vos et al. (2012) focussing more on attitudes towards specific travel modes - found that about half of the respondents lived in a neighbourhood discouraging the use of their preferred mode, i.e., urban residents who liked to drive and suburban residents preferring public transport or active travel. Other studies, using a similar approach (i.e., a $2 \times 2$ classification based on neighbourhood type and travel-related attitude), confirmed that people often do not live in a neighbourhood which is consistent with their travel preferences (e.g., Cho \& Rodriguez, 2014; De Vos et al., 2016a; Kajosaari et al., 2019; Kamruzzaman et al., 2013a; Kumar et al., 2018). A residential dissonance can be caused, for instance, by budgetary constraints, various (or competing) residential preferences within households, or the preferred type of neighbourhood being too distant from the work location. Furthermore, the residential location choice is influenced by a wide range of elements (including the supply of housing and various urban policies) and the choice of where to live is often based on reasons other than transport, such as characteristics of the dwelling and amenities available in the neighbourhood (Ettema \& Nieuwenhuis, 2017; Wolday et al.,2018). In analogy with the travel mode choice, it can be expected that a dissonance will occur more easily when the choice of where to live is not a free choice. According to Lin et al. (2017), having a lot of freedom to choose where to live (i.e., self-selection) mostly (but not always) results in travel attitudes being congruent with the chosen neighbourhood, while a residential location choice with limited freedom (referred to as residential determination) might easily result in a dissonance between attitudes and chosen neighbourhood.

Although a considerable amount of studies has analysed differences in satisfaction with the chosen neighbourhood according to the type of residential location (e.g., De Vos et al., 2016b; Lovejoy et al., 2010), only two studies measured the direct effect of residential dissonance on satisfaction with (aspects of) the place of residence. Cao and Wang (2016) indicate that living in a non-desired residential neighbourhood results in low levels of residential satisfaction, while van de Coevering et al. (2018) found that residential dissonance negatively affects people's satisfaction with the distance to shopping facilities. Some studies have indicated that such a low residential satisfaction results in an intention to relocate to another type of neighbourhood (Ginsberg \& Churchman, 1984; Oh, 2003; Speare, 1974). Kamruzzaman et al. (2013b) analysed the direct effect of residential dissonance on residential mobility, but only found limited support for this relationship. Since a residential relocation

\footnotetext{
${ }^{3}$ There could be dissonance between one's neighbourhood and many other residential characteristics (school quality, green space, housing type, etc.), but here we focus on travel-related elements of residential dissonance.
} 
involves substantial monetary as well as nonmonetary costs, a reduction in residential dissonance by relocating is not always obvious (De Vos et al., 2012). In his theory of cognitive dissonance, Festinger (1957, p. 25) describes the residential location choice as follows: "A person may, for example, have spent a lot of money to purchase a house. If for any reason he now wants to change, that is, live in a different house or different neighborhood, he must endure the discomforts of moving and the possible financial loss involved in selling the house".

An alternative way to reduce residential dissonance is by changing attitudes towards travel. For instance, a person ending up living in an urban neighbourhood - although having a preference for living in a suburban area and driving a car - might change his/her attitudes so they better match with the surrounding he/she lives in. This person might appreciate the neighbourhood's stimulated travel modes (i.e., public transport and active travel in urban areas), whereby attitudes towards these modes - and also attitudes towards the neighbourhood - improve. Although some studies have suggested that the built environment can impact people's travel attitudes, whether or not through travel patterns stimulated by the new built environment (e.g., Chatman, 2009; Handy et al., 2005; Lin et al., 2017; Næss, 2009; van Wee et al., 2019), only a limited number of studies have actually measured it. Bagley and Mokhtarian (2002) found no significant effects of respondents' residential location on travelrelated attitudes, while van de Coevering et al. (2016) indicate that living far away from a railway station negatively affects attitudes towards public transport, while positively affecting attitudes towards driving. Other studies - using cross-sectional structural equation models to analyse links between the built environment, travel behaviour and attitudes - found significant reciprocal relationships between people's residential location and their travel attitudes (de Abreu e Silva, 2014; Ewing et al., 2016; Lin et al., 2017; Van Acker et al., 2014). Two studies focussing on recently relocated residents found that attitudes towards travel modes significantly changed - i.e, became more in line with travel stimulated by the new built environment - after respondents moved (De Vos et al., 2018; Wang \& Lin, 2019).

Building from the literature summarised above, Figure 3 shows a potential process of residential dissonance reduction. A dissonance between travel-related attitudes and the chosen residential neighbourhood might result in relatively low levels of satisfaction with the neighbourhood people live in. Due to this discomfort, people could choose to relocate to a neighbourhood that better matches with their (travel) preferences. In case relocating is not feasible, people's travel attitudes might change in order to reduce the residential dissonance. Although - parallel to travel mode dissonance reduction - the (residential dissonance reduction) process shown in Figure 3 should also be regarded as a cyclical process, this process will take place far less frequent as people do not relocate easily.

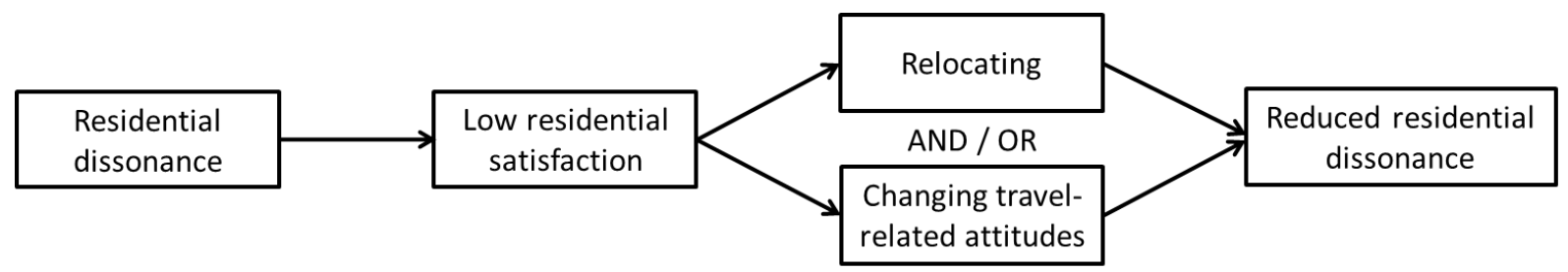

Figure 3. Residential dissonance (reduction) 


\subsection{Relationships between travel mode choice and residential location choice}

Although Figures 2 and 3 represent travel mode dissonance and residential dissonance as two independent concepts, certain links between them are possible (Figure 4). First of all, residential dissonance can affect travel mode dissonance. People who do not live in a neighbourhood consistent with their travel attitudes might have to adjust their travel behaviour and (frequently) use a nonpreferred travel mode stimulated by the built environment characteristics (e.g., Cao 2015; Cho \& Rodriguez, 2014; De Vos et al., 2012; Frank et al., 2007; Schwanen \& Mokhtarian, 2005a). A suburban resident that likes to cycle, for instance, might have to use a motorised travel mode at least once in a while since destinations are often not within cycling distances in low-density suburbs. In sum, a certain level of residential dissonance might easily result in a certain level of travel mode dissonance. As a result, residential dissonance can indirectly affect travel satisfaction. De Vos et al. (2016a) found that a positive stance towards living in a suburban-style environment and travelling by car had a significantly negative effect on travel satisfaction for urban residents, while no significant negative effect of urban preferences on travel satisfaction of suburban residents was found.

Since people's residential neighbourhood has an important impact on their travel behaviour - and can constrain the use of certain (valued) travel modes - it is likely to assume that travel satisfaction influences residential satisfaction. The suburban bicycle enthusiast might not be fully satisfied with the chosen neighbourhood as it does not enable him/her to cycle frequently. As a result, low levels of travel satisfaction might increase people's tendency to relocate to a different type of neighbourhood, as a different neighbourhood might allow more frequent trips using preferred modes (De Vos \& Witlox, 2017). ${ }^{4}$ This train of thought is in line with studies suggesting that people choose to live in neighbourhoods enabling them to have satisfying trips (Cao \& Ettema, 2014; De Vos \& Witlox, 2016).

As indicated earlier, changing mode choice can reduce travel mode dissonance, just as relocating can reduce residential dissonance. On the other hand, both travel mode dissonance and residential dissonance can be reduced simultaneously by changing travel-related attitudes. The suburban resident who likes to cycle but is often forced to travel by car might reduce both types of dissonances by improving his/her attitudes towards car use. Finally, it is also possible that a reduction in travel mode dissonance goes hand in hand with a reduction in residential dissonance. When people bring their travel attitudes more in line with their chosen travel modes, the built environment no longer stimulates the use of a non-preferred mode, and dissonance between travel-related attitudes and the residential location has decreased. On the other hand, when people move to a neighbourhood that better fits with travel-related attitudes - and thereby reducing residential dissonance - it will become easier for them to travel with an appreciated travel mode, reducing travel mode dissonance.

\footnotetext{
${ }^{4}$ On the other hand, being very satisfied with the current dwelling and/or residential neighbourhood (amenities) might be a reason for people to put up with unsatisfying travel patterns.
} 


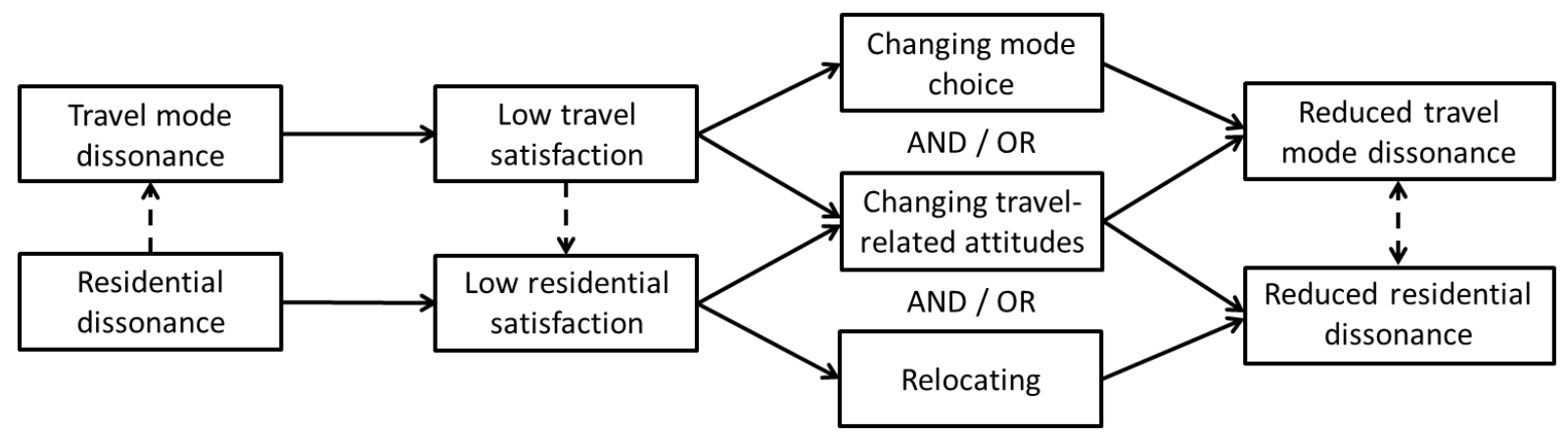

Figure 4: Possible relationships between travel mode dissonance (reduction) and residential dissonance (reduction)

\section{Discussion of dissonance development and stability}

Besides looking at a reduction in travel mode dissonance and residential dissonance (Section 2), it is also worth discussing the development or increase of travel mode dissonance and residential dissonance (Section 3.1), and a possible stable situation of dissonance/consonance between attitudes and the chosen travel mode and residential neighbourhood (Section 3.2).

\subsection{Development of cognitive dissonance}

As indicated before, Festinger's theory $(1957,1964)$ states that people will reduce their dissonance by either changing behaviour or by changing attitudes. Of course, when dissonance keeps reducing, dissonance will eventually cease to exist. This indicates that cognitive dissonance also must pop up or grow at a certain point (Brehm \& Cohen, 1962; Festinger, 1957). Cognitive dissonance might increase or develop every time a choice has been made, especially when there is limited freedom to choose (i.e., "forced compliance"), or when people have to choose between negatively perceived alternatives. For instance, residential dissonance is likely to occur when people have limited freedom to choose a new neighbourhood (e.g., due to monetary budget or other restrictions), while travel mode dissonance might occur when a car lover can only choose between public transport use or active travel (e.g., due to legal/financial inability to own or operate a car). It should be noted that dissonance can also occur when people choose a preferred alternative, since the not-chosen alternative might also had some positive attributes which cannot be enjoyed when not choosing it. A person choosing to live in an urban neighbourhood due to good public transport and cycling facilities might still envy people living in the countryside, for instance because they have better access to green spaces. In sum, every choice made could reduce dissonance (i.e., changing behaviour to reduce discomfort) and/or increase dissonance.

A second way in which dissonance can occur is when a person is exposed to information that is not consistent with that person's current attitude, possibly affecting that attitude. For instance, a carloving suburban resident might be exposed to studies indicating that urban sprawl and car use result in the loss of wildlife area and in an increase of air pollution. As a result, this person might become more environmentally aware, which is inconsistent with his/her way of living. Furthermore, new travel experiences might also affect people's travel attitudes by providing new or updated information. AbouZeid et al. (2012) and Fujii and Kitamura (2003) found improved attitudes towards public transport of habitual car users switching to public transport (after receiving a temporary free public transport pass). They argue that original negative attitudes towards public transport (possibly resulting from misperceptions regarding public transport) were corrected by new information gained through direct 
experience of using public transport. Hence, similar to behaviour, changes in attitudes can both decrease and increase cognitive dissonance (Brehm \& Cohen, 1962; Festinger, 1957).

\subsection{Stable situation of dissonance and consonance}

It should also be noted that cognitive dissonance, once created, may persist. Festinger (1957, p.6) states that "There is no guarantee that the person will be able to reduce or remove the dissonance. The hypothetical smoker may find that the process of giving up smoking is too painful for him to endure. He might try to find facts and opinions of others to support the view that smoking is not harmful, but these attempts might fail. He might then remain in the situation where he continues to smoke and continues to know that smoking is harmful." In terms of travel behaviour, it might be possible that a considerable share of public transport users is not able to remove their dissonance due to various constraints. Numerous studies on travel satisfaction indicate that public transport users are less satisfied with their trips compared to people using other modes (e.g., De Vos et al., 2016a; Morris and Guerra 2015; St-Louis et al. 2014), while studies also indicate that attitudes towards public transport are more negative compared to attitudes towards car use and active travel (e.g., Anable \& Gatersleben, 2005; Kroesen et al., 2017). De Vos (2018) found these negative attitudes and satisfaction levels of public transport users for respondents in the same sample. This indicates that public transport users might be stuck in a situation where they (have to) use public transport although having negative attitudes towards public transport, resulting in low travel satisfaction levels. These "captive" public transport users may face various constraints: they might not have a driver's license, might not be financially able to buy a car (e.g., Beimborn et al., 2003; Jacques et al., 2013), or might not be able to walk or cycle due to long distances or low fitness levels. In fact, their negative experiences and lack of satisfaction with public transit use might contribute to maintaining their negative attitudes towards this mode.

On the other hand, it is also possible that people experience a continuing situation of cognitive consonance in which attitudes and behaviour are consistent with each other. A person might choose a certain travel mode which he/she prefers, enjoys the trip undertaken with this mode - positively affecting the attitude towards that mode - and as a result chooses to continue using this mode. De Vos et al. (2019) have found such a positive reinforcing affect for people walking and cycling. Such a stable situation of cognitive consonance might also create travel habits in which people do not weigh the pros and cons of the available alternatives but choose the mode that previously provided them satisfying trips (De Vos \& Witlox, 2017), possibly resulting in "loyal" mode users (Fu et al., 2018; Lai \& Chen, 2011; van Lierop et al., 2018).

\section{Conclusion: Policy recommendations and future research needs}

In this paper we have examined the complex and dynamic relationships between travel-related behaviours and attitudes in light of cognitive dissonance theory. Our survey of the literature found that most travel behaviour studies use cognitive dissonance theory to potentially explain results, not as an overarching study design or analysis framework. At the same time, there is some evidence consistent with such a framework, and we have indicated how a dissonance between travel-related attitudes and the choice of travel mode and residential location can help explain (i) satisfaction levels with travel and the residential location, (ii) changes in travel mode and the residential location, and (iii) changes in travel-related attitudes. Our review paper contributes conceptual frameworks summarising the 
literature and explanations based in cognitive dissonance theory to help understand these complex and dynamic relationships. In the paragraphs below, we also describe implications for policymaking and future research.

The reconceptualization of these dynamic processes from this paper can be helpful not only for future travel behaviour studies, but also from a policy perspective. New insights can help in creating policy measures stimulating sustainable travel patterns and improving people's well-being. Based on the literature described - and models conceptualised - in the previous sections, it can be argued that policy makers should try to improve people's attitudes towards active travel and public transport. These attitudes will not only stimulate people to walk, cycle and use public transport more often, it will also stimulate them to live in urban-style neighbourhoods, enabling them to easily travel by these (desired) modes. Improving attitudes towards active travel and public transport could be realised by making these modes more convenient and pleasant, for instance by creating separated and barrier-free cycling lanes, wide, well-lit sidewalks and safe crossings for pedestrians, and improving comfort and punctuality of public transport (see, e.g., Susilo \& Cats, 2014). A higher frequency of active travel and public transport and more satisfying trips using these modes will likely improve attitudes towards these modes, further stimulating their use and living in urban neighbourhoods. Policies making it easier for people to move to (walkable) urban neighbourhoods, such as providing more and affordable housing in urban areas, could also improve consonance and satisfaction by allowing suburbanites with positive attitudes towards active travel and public transport to realise their travel preferences through residential relocation. Additionally, more satisfying trips are likely to result in higher levels of subjective well-being, partly because they can improve the performance of - and increase satisfaction with activities at trip destinations (e.g., Chatterjee et al., 2020; De Vos, 2019; Ettema et al., 2010).

Linking back to the models described in Figures 2, 3 and 4, improving attitudes towards active travel and public transport can either (i) increase consonance of those living in urban neighbourhoods or travelling by car alternatives, or (ii) increase dissonance for those living in more suburban-style neighbourhoods frequently travelling by car. For the former group, behaviour will most likely not change since attitudes become even more in line with current behaviour. For the latter group, people might be inclined to change their behaviour due to increased levels of dissonance between behaviour and attitudes. They might be inclined to reduce car use and/or move to more urban typeneighbourhoods in order to increase levels of consonance and satisfaction.

Since current studies on the extent and outcomes of travel mode dissonance and residential dissonance remain scarce, and most of them only briefly deal with dissonance without taken into account the relationships between dissonance, satisfaction, attitudes and behaviour as presented in Figures $2-4$, we identify four avenues for further research. First, the cognitive dissonance theory can provide valuable insights into how people perceive their trips. Although many studies have indicated that the chosen travel mode has an important effect on travel satisfaction, not a lot of studies have looked at the (potentially strong) effect of travel mode dissonance - whether the chosen mode is a desired mode, or whether people are forced to use that mode - on travel satisfaction. Additionally, the effect of residential dissonance on residential satisfaction is also under-explored, requiring further analysis. Second, in spite of many travel behaviour studies considering attitudes to be stable constructs affecting behaviour (often based on Ajzen's theory of planned behaviour (1991)), the cognitive dissonance theory can shed new light on possible dynamics in travel-related attitudes. Future studies 
should therefore analyse the effect of travel mode dissonance and residential dissonance on travel attitudes. Third, although travel studies often regard (travel) behaviour as an outcome of (relatively stable) elements such as budgetary or built environment constraints and attitudes, further research should analyse how behaviour (e.g., travel mode choice, residential location choice) is affected by (travel or residential) dissatisfaction caused by cognitive dissonance. Of course, measuring changes in behaviour - but also in travel attitudes (previous avenue for further research) - requires longitudinal data. Fourth, analysing interactions between travel mode dissonance (reduction) and residential dissonance (reduction), as shown in Figure 4, can provide new insights into how people's residential environment interacts with their travel behaviour. A dissonance (reduction) between attitudes and travel mode might be linked with a dissonance (reduction) between attitudes and the residential location. Furthermore, residential satisfaction might be affected by how (negatively or positively) people perceive their daily travel patterns. Overall, we hope our findings and insights in this review encourage future research endeavours that illuminate our understanding of the dynamic relationships between attitudes, behaviour and satisfaction from a travel point of view.

Of course, measuring the models shown in Figures $2-4$ is not obvious. Multiple approaches can be identified, but all have their limitations. Traditional social psychology methods for analysing cognitive dissonance typically involve true experiments with reference and control groups and some immediate or low-effort treatment or intervention (Harmon-Jones \& Harmon-Jones, 2007). However, such laboratory- or classroom-based experimental designs are usually inappropriate for analysing (residential or) travel behaviour and attitude changes. In these cases, natural experiments or observational studies are more appropriate. Cross-sectional structural equations models can provide some evidence for the direction of influence between behaviour, attitudes, and satisfaction levels. However, no robust conclusions on the causal nature of processes can be drawn from cross-sectional data (due to a lack of time precedence), even when applying structural equation modelling. This means that true longitudinal data - in combination with complex methodologies (e.g., crossed-lagged structural equation modelling) - is needed to measure the links between behaviour, attitudes and satisfaction. Longitudinal data, however, are generally scarce in travel behaviour research (but also in other domains), as they are expensive, time consuming and impose a high respondent burden. Although examples of longitudinal (national) household surveys with large samples and multiple waves exist, questions concerning travel and residential location choice are often limited, mostly leaving out questions regarding attitudes and satisfaction. Qualitative methods - resulting from in-depth interviews or focus groups - can potentially provide useful insights on the causality of effects, sometimes beyond what cross-sectional quantitative data can do. Focus groups of recently relocated residents and people that have recently changed their travel patterns might be of particular interest. ${ }^{5}$ Focus groups are probably most in line with the experimental design in which the cognitive dissonance theory is often analysed. However, the possibility of severe biases in case of direct questioning (e.g., memory bias, consistency bias, social desirability) and mostly small sample sizes (resulting in limited representativeness) can be regarded as limitations.

In sum, future studies should - in order to identify our proposed avenues for further research - focus on creating an appropriate design for measuring the outlined models. Suitable research methods might

\footnotetext{
${ }^{5}$ Changing travel patterns might result from a residential or job relocation or from new travel opportunities/limitations such as the implementation of Sustainable Urban Mobility Plans, Mobility-as-a-Service schemes, road pricing, and new metro/light rail services.
} 
differ from the methods commonly used in travel behaviour studies, and will likely require the collection of detailed longitudinal data. Inadequacies of existing research methods in the travel behaviour field might be a reason why full examination of the process of cognitive dissonance (reduction) in relationship with travel is currently lacking.

\section{Acknowledgments}

This work was supported by the Research Foundation - Flanders (FWO) under grant 12F2519N. The authors would like to thank the three anonymous reviewers for their constructive comments and suggestions, making it possible to improve this paper.

\section{References}

Abou-Zeid, M., Ben-Akiva, M., 2012. Travel mode switching: comparison of findings from two public transportation experiments. Transport Policy 24, 48-59.

Abou-Zeid, M., Fujii, S., 2016. Travel satisfaction effects of changes in public transport usage. Transportation 43 (2), 301-314.

Ajzen, I., 1991. The theory of planned behavior. Organizational Behavior and Human Decision Processes 50 (2), 179-211.

Anable, J., Gatersleben, B., 2005. All work and no play? The role of instrumental and affective factors in work and leisure journeys by different travel modes. Transportation Research Part A 39 (2-3), 163181.

Aronson, E., 1992. The return of the repressed: Dissonance theory makes a comeback. Psychological Inquiry 3 (4), 303-311.

Bagley, M.N., Mokhtarian, P.L., 2002. The impact of residential neighborhood type on travel behavior: a structural equations modeling approach. The Annals of Regional Science 36 (2), 279-297

Beimborn, E., Greenwald, M., Jin, X., 2003. Accessibility, Connectivity, and Captivity: Impacts on Transit Choice. Transportation Research Record 1835, 1-9.

Beirão, G., Cabral, J.A.S., 2007. Understanding attitudes towards public transport and private car: a qualitative study. Transport Policy 14 (6), 478-489.

Belgiawan, P.F., Schmöcker, J.-D., Fujii, S., 2016. Understanding car ownership motivations among Indonesian students. International Journal of Sustainable Transportation 10 (4), 295-307.

Bem, D.J., 1967. Self-perception: An alternative interpretation of cognitive dissonance phenomena. Psychological Review 74 (3), 183-200.

Bohner, G., Wänke, M., 2002. Attitudes and attitude change. Psychology Press, Hove.

Brehm, J.W., Cohen, A.R., 1962. Explorations in cognitive dissonance. John Wiley \& Sons, New York.

Cao, J., 2015. Heterogeneous effects of neighborhood type on commute mode choice: An exploration of residential dissonance in the Twin Cities. Journal of Transport Geography 48, 188-196.

Cao, J., Ettema, D., 2014. Satisfaction with travel and residential self-selection: How do preferences moderate the impact of the Hiawatha Light Rail Transit line? Journal of Transport and Land Use 7 (3), 93-108. 
Cao, J., Mokhtarian, P.L., Handy, S.L., 2009. Examining the impacts of residential self-selection on travel behaviour: a focus on empirical findings. Transport Reviews 29 (3), 359-395.

Cao, J., Wang, D., 2016. Environmental correlates of residential satisfaction: An exploration of mismatched neighborhood characteristics in the Twin Cities. Landscape and Urban Planning 150, 2635.

Chatman, D.G., 2009. Residential choice, the built environment, and nonwork travel: evidence using new data and methods. Environment and Planning A 41 (5), 1072-1089.

Chatterjee, K., Chng, S., Clark, B., Davis, A., De Vos, J., Ettema, D., Handy, S., Martin, A., Reardon, L., 2020. Commuting and wellbeing: a critical overview of the literature with implications for policy and future research. Transport Reviews 40 (1), 5-34.

Chen, C.-F., Lai, W.-T., 2011. The effects of rational and habitual factors on mode choice behaviors in a motorcycle-dependent region: Evidence from Taiwan. Transport Policy 18 (5), 711-718.

Cho, G.-H., Rodriguez, D.A., 2014. The influence of residential dissonance on physical activity and walking: evidence from the Montgomery County, MD, and Twin Cities, MN, areas. Journal of Transport Geography 41, 259-267.

Clore, G.L., Schnall, S., 2005. The influence of affect on attitude. In: Albarracín, D., Johnson, B.T., Zanna, M.P. (Eds.) The handbook of attitudes (pp. 437-489). Lawrence Erlbaum Associates, Mahwah.

Cooper., J., 2007. Cognitive dissonance. Fifty years of a classic theory. Sage Publications, London.

Crano, W.D., Prislin, R., 2011. Attitudes and attitude change. Psychology Press, New York.

de Abreu e Silva, J., 2014. Spatial self-selection in land-use-travel behavior interactions: Accounting simultaneously for attitudes and socioeconomic characteristics. Journal of Transport and Land Use 7 (2), 63-84.

De Vos, J., 2018. Do people travel with their preferred travel mode? Analysing the extent of travel mode dissonance and its effect on travel satisfaction. Transportation Research Part A 117, 261-274.

De Vos, J., 2019. Analysing the effect of trip satisfaction on satisfaction with the leisure activity at the destination of the trip, in relationship with life satisfaction. Transportation 46 (3), 623-645.

De Vos, J., Derudder, B., Van Acker, V., Witlox, F., 2012. Reducing car use: changing attitudes or relocating? The influence of residential dissonance on travel behavior. Journal of Transport Geography 22, 1-9.

De Vos, J., Ettema, D., Witlox, F., 2018. Changing travel behaviour and attitudes following a residential relocation. Journal of Transport Geography 73, 131-147.

De Vos, J., Schwanen, T., Van Acker, V., Witlox, F., 2019. Do satisfying walking and cycling trips result in more future trips with active travel modes? An exploratory study. International Journal of Sustainable Transportation 13 (3), 180-196.

De Vos, J., Mokhtarian, P.L., Schwanen, T., Van Acker, V., Witlox, F., 2016a. Travel mode choice and travel satisfaction: bridging the gap between decision utility and experienced utility. Transportation 43 (5), 771-796.

De Vos, J., Witlox, F., 2016. Do people live in urban neighbourhoods because they do not like to travel? Analysing an alternative residential self-selection hypothesis. Travel Behaviour and Society 4, 29-39. 
De Vos, J., Witlox, F., 2017. Travel satisfaction revisited. On the pivotal role of travel satisfaction in conceptualising a travel behaviour process. Transportation Research Part A 106, 364-373.

De Vos, J., Van Acker, V., Witlox, F., 2016b. Urban sprawl: Neighbourhood dissatisfaction and urban preferences. Some evidence from Flanders. Urban Geography 37 (6), 839-862.

Dobson, R., Dunbar, F., Smith, C.J., Reibstein, D., Lovelock, C., 1978. Structural models for the analysis of traveler attitudebehavior relationships. Transportation 7 (4), 351-363.

Domarchi, C., Tudela, A., González, A., 2008. Effect of attitudes, habit and affective appraisal on mode choice: An application to university workers. Transportation 35 (5), 585-599.

Eagly, A.H., Chaiken, S., 1993. The psychology of attitudes. Harcourt Brace Jovanovich, Fort Worth.

Ettema, D., Gärling, T., Olsson, L.E., Friman, M., 2010. Out-of-home activities, daily travel, and subjective wellbeing. Transportation Research Part A 44 (9), 723-732.

Ettema, D., Nieuwenhuis, R., 2017. Residential self-selection and travel behaviour: what are the effects of attitudes, reasons for location choice and the built environment? Journal of Transport Geography $59,146-155$.

Ewing, R., Cervero, R., 2001. Travel and the built environment: a synthesis. Transportation research Record 1780, 87-114.

Ewing, R., Cervero, R., 2010. Travel and the built environment. A meta-analysis. Journal of the American Planning Association 76 (3), 265-294.

Ewing, R., Hamidi, S., Grace, J.B., 2016. Compact development and VMT-Environmental determinism, self-selection, or some of both? Environment and Planning B 43 (4), 737-755.

Festinger, L., 1957. Theory of Cognitive Dissonance. Stanford University Press, Stanford.

Festinger, L., 1964. Conflict, decision, and dissonance. Stanford University Press, Stanford.

Frank, L.D., Saelens, B.E., Powell, K.E., Chapman, J.E., 2007. Stepping towards causation: do built environments or neighborhood and travel preferences explain physical activity, driving, and obesity? Social Science \& Medicine 65, 1898-1914.

Fu, X.-M., Zhang, J.-H., Chan, F.T.S., 2018. Determinants of loyalty to public transit: A model integrating Satisfaction-Loyalty Theory and Expectation-Confirmation Theory. Transportation Research Part A 113, 476-490.

Fujii, S., Kitamura, R., 2003. What does a one-month free bus ticket do to habitual drivers? Transportation 30 (1), 81-95.

Ginsberg, Y., Churchman, A., 1984. Housing satisfaction and intention to move: Their explanatory variables. Socio-Economic Planning Sciences 18 (6), 425-431.

Golob, T.F., 2001. Joint models of attitudes and behavior in evaluation of the San Diego I-15 congestion pricing project. Transportation Research Part A 35 (6), 495-514.

Golob, T.F., Horowitz, A.D., Wachs, M., 1979. Attitude-behaviour relationships in travel-demand modelling. In: Hensher, D.A., Stopher, P.R. (Eds.) Behavioural Travel Modelling (pp. 739-757). Croom Helm, London. 
Handy, S.L., Cao, J., Mokhtarian, P.L., 2005. Correlation or causality between the built environment and travel behavior? Evidence from Northern California. Transportation Research D 10 (6), 427-444.

Harmon-Jones, E., Harmon-Jones, C., 2007. Cognitive dissonance theory after 50 years of development. Zeitschrift für Sozialpsychologie 38, 7-16.

Harmon-Jones, E., Mills, J., 1999. Cognitive dissonance: progress on a pivotal theory in social psychology. American Psychological Association, Washington D.C.

Heider, F., 1958. The psychology of interpersonal relations. Lawrence Erlbaum Associates, Hillsdale.

Horowitz, A.D., 1978. A cognitive dissonance approach to attitudinal modeling in travel behavior research. Paper presented at the $57^{\text {th }}$ Annual Meeting of the Transportation Research Board, Washington, D.C.

Huang, X., Cao, J., Cao, X., Yin, J., 2016. How does the propensity of living near rail transit moderate the influence of rail transit on transit trip frequency in Xi'an? Journal of Transport Geography 54, 194204.

Jacques, C., Manaugh, K., El-Geneidy, A., 2013. Rescuing the captive [mode] user: an alternative approach to transport market segmentation. Transportation 40 (3), 625-645.

Kahneman, D., Wakker, P.P., Sarin, R., 1997. Back to Bentham? Explorations of experienced utility. Quarterly Journal of Economics 112 (2), 375-405.

Kajosaari, A., Hasanzadeh, K., Kyttä, M., 2019. Residential dissonance and walking for transport. Journal of Transport Geography 74, 134-144.

Kamruzzaman, M., Baker, D., Turrell, G., 2015. Do dissonants in transit oriented development adjust commuting travel behaviour? European Journal of Transport and Infrastructure Research 15 (1), 6677.

Kamruzzaman, M., Baker, D., Washington, S., Turrell, G., 2013a. Residential dissonance and mode choice. Journal of Transport Geography 33, 12-28.

Kamruzzaman, M., Baker, D., Washington, S., Turrell, G., 2016. Determinants of residential dissonance: Implications for transit-oriented development in Brisbane. International Journal of Sustainable Transportation 10 (10), 960-974.

Kamruzzaman, M., Washington, S., Baker, D., Turrell, G., 2013b. Does Residential Dissonance Affect Residential Mobility? Transportation Research Record 2344, 59-67.

Kaplan, S., de Abreu e Silva, J., Di Ciommo, F., 2014. The relationship between young people's transit use and their perceptions of equity concepts in transit service provision. Transport Policy 36, 79-87.

Kitamura, R., Mokhtarian, P.L., Laidet, L., 1997. A micro-analysis of land use and travel in five neighborhoods in the San Francisco Bay Area. Transportation 24 (2), 125-158.

Kroesen, M., Handy, S., Chorus, C., 2017. Do attitudes cause behavior or vice versa? An alternative conceptualization of the attitude-behavior relationship in travel behavior modeling. Transportation Research Part A 101, 190-202.

Kumar, P.P., Sekhar, C.R., Parida, M., 2018. Residential dissonance in TOD neighborhoods. Journal of Transport Geography 72, 166-177. 
Lai, W.-T., Chen, C.-F., 2011. Behavioral intentions of public transit passengers - The roles of service quality, perceived value, satisfaction and involvement. Transport Policy 18 (2), 318-325.

Li, J., 2018. Residential and transit decisions: Insights from focus groups of neighborhoods around transit stations. Transport Policy 63, 1-9.

Lin, T., Wang, D., Guan, X., 2017. The built environment, travel attitude, and travel behaviour: Residential self-selection or residential determination? Journal of Transport Geography 65, 111-122.

Lovejoy, K., Handy, S., Mokhtarian, P.L., 2010. Neighborhood satisfaction in suburban versus traditional environments: An evaluation of contributing characteristics in eight California neighborhoods. Landscape and Urban Planning 97 (1), 37-48.

Manaugh, K., El-Geneidy, A., 2015. The importance of neighborhood type dissonance in understanding the effect of the built environment on travel behavior. Journal of Transport and Land Use 8 (2), 45-57.

Milakis, D., Cervero, R., van Wee, B., Maat, K., 2015. Do people consider an acceptable travel time? Evidence from Berkeley, CA. Journal of Transport Geography 44, 76-86.

Morris, E.A., Guerra, E., 2015. Mood and mode: Does how we travel affect how we feel? Transportation $42(1), 25-43$.

Næss, P., 2009. Residential self-selection and appropriate control variables in land use: Travel studies. Transport Reviews 29 (3), 293-324.

Næss, P., 2010. Residential location, travel, and energy use in the Hangzhou metropolitan area. Journal of Transport and Land Use 3, 27-59.

Næss, P., 2014. Tempest in a teapot: the exaggerated problem of transport-related residential selfselection as a source of error in empirical studies. Journal of Transport and Land Use 7 (3), 57-79.

Oh, J.H., 2003. Social bonds and the migration intentions of elderly urban residents: The mediating effect of residential satisfaction. Population Research and Policy Review 22 (2), 127-146.

Páez, A., 2013. Mapping travelers' attitudes: does space matter? Journal of Transport Geography 26, 117-125.

Reibstein, D.J., Lovelock, C.H., Dobson, R.P., 1980. The direction of causality between perceptions, affect, and behavior: an application to travel behavior. Journal of Consumer Research 6 (4), 370-376.

Russell, J.A., Lanius, L.F., 1984. Adaptation level and the affective appraisal of environments. Journal of Environmental Psychology 4 (2), 119-135.

Schwanen, T., Mokhtarian, P.L., 2004. The extent and determinants of dissonance between actual and preferred residential neighborhood type. Environment and Planning B 31 (5), 759-784.

Schwanen, T., Mokhtarian, P.L., 2005a. What affects commute mode choice, neighbourhood physical structure or preferences toward neighborhoods? Journal of Transport Geography 13 (1), 83-99.

Schwanen, T., Mokhtarian, P.L., 2005b. What if you live in the wrong neighborhood? The impact of residential neighbourhood type dissonance on distance travelled. Transportation Research Part D 10 (2), 127-151.

Singleton, P.A., 2017. Exploring the positive utility of travel and mode choice (doctoral dissertation). Portland State University, Portland. https://doi.org/10.15760/etd.3447 
Singleton, P.A., 2019. Walking (and cycling) to well-being: Modal and other determinants of subjective well-being during the commute. Travel Behaviour and Society 16, 249-261.

Speare, A., 1974. Residential satisfaction as an intervening variable in residential mobility. Demography $11(2), 173-188$.

Stark, J., Meschik., M., Singleton, P.A., Schützhofer, B., 2018. Active school travel, attitudes and psychological well-being of children. Journal of Transport Geography 56, 453-465.

Stark, J., Singleton, P.A., UhIman, T., 2019. Exploring children's school travel, psychological well-being, and travel-related attitudes: Evidence from primary and secondary school children in Vienna, Austria. Travel Behaviour and Society 16, 118-130.

St-Louis, E., Manaugh, K., van Lierop, D., El-Geneidy, A., 2014. The happy commuter: a comparison of commuter satisfaction across modes. Transportation Research Part F 26, 160-170.

Susilo, Y.O., Cats, O., 2014. Exploring key determinants of travel satisfaction for multi-modal trips by different traveler groups. Transportation Research Part A 67, 366-380.

Tardiff, T.J., 1977. Causal inferences involving transportation attitudes and behavior. Transportation Research 11, 397-404.

Thigpen, C., 2019. Do bicycling experiences and exposure influence bicycling skills and attitudes? Evidence from a bicycle-friendly university. Transportation Research Part A 123, 68-79.

Ton, D., Zomer, L.-B., Schneider, F., Hoogendoorn-Lanser, S., Duives, D., Cats, O., Hoogendoorn, S., 2019. Latent classes of daily mobility patterns: the relationship with attitudes towards modes. Transportation. https://doi.org/10.1007/s11116-019-09975-9

Triandis, H.C., 1971. Attitude and attitude change. John Wiley \& Sons, New York.

Triandis, H.C., 1977. Interpersonal Behavior. Brooks/Cole, Monterey.

Van Acker, V., Mokhtarian, P.L., Witlox, F., 2014. Car availability explained by the structural relationships between lifestyles, residential location, and underlying residential and travel attitudes. Transport Policy 35, 88-99.

van de Coevering, P., Maat, K., Kroesen, M., van Wee, B., 2016. Causal effects of built environment characteristics on travel behavior: A longitudinal approach. European Journal of Transport and Infrastructure Research 16, 674-697.

van de Coevering, P., Maat, K., van Wee, B., 2018. Residential self-selection, reverse causality and residential dissonance. A latent class transition model of interactions between the built environment, travel attitudes and travel behavior. Transportation Research Part A 118, 466-479.

van Lierop, D., Badami, M. G., El-Geneidy, A., 2018. What influences satisfaction and loyalty in public transport? A review of the literature. Transport Reviews 38 (1), 52-72.

van Wee, B., De Vos, J., Maat, K., 2019. Impacts of the built environment and travel behaviour on attitudes: Theories underpinning the reverse causality hypothesis. Journal of Transport Geography 80, 102540.

van Wee, B., Holwerda, H., van Baren, R., 2002. Preferences for modes, residential location and travel behaviour: The relevance for land-use impacts on mobility. European Journal of Transport and Infrastructure Research 2(3/4), 305-316. 
Wang, T., Chen, C., 2012. Attitudes, mode switching behavior, and the built environment: A longitudinal study in the Puget Sound Region. Transportation Research Part A 46 (10), 1594-1607.

Wang, D., Lin, T., 2019. Built environment, travel behavior, and residential self-selection: a study based on panel data from Beijing, China. Transportation 46 (1), 51-74.

Wicklund, R.A., Brehm, J.W., 1976. Perspectives on cognitive dissonance. Lawrence Erlbaum Associates, Hillsdale.

Wolday, F., Cao, J., Næss, P., 2018. Examining factors that keep residents with high transit preference away from transit-rich zones and associated behavior outcomes. Journal of Transport Geography 66, 224-234.

Ye, R., Titheridge, H., 2017. Satisfaction with the commute: The role of travel mode choice, built environment and attitudes. Transportation Research Part D 52B, 535-547.

Ye, R., Titheridge, H., 2019. The determinants of commuting satisfaction in low-income population: A case study of Xi'an, China. Travel Behaviour and Society 16, 272-283.

Zanna, M.P., Rempel, J.K., 1988. Attitudes: a new look at an old concept. In: Bar-Tal, D., Kruglanski, A. (Eds.) The Social Psychology of Knowledge (pp. 315-334). Cambridge University Press, Cambridge.

Zarabi, Z., Gerber, P., Lord, S., 2019. Travel satisfaction vs. life satisfaction: A weighted decision-making approach. Sustainability 11 (19), 5309. 